\title{
Burden of Adenovirus, Astrovirus, Norovirus and Rotavirus Gastroenteritis in Egyptian Children during 2000-2017
}

\section{Mohamed NF Shaheen*}

Environmental Virology Laboratory, Water Pollution Research Department, Environmental Research Division, National Research Center, Giza, Egypt

\begin{abstract}
Enteric viruses are the leading cause of severe dehydrating diarrhea among children, worldwide. The aim of this review was to estimate the burden of adenovirus (AdV), astrovirus (AstV), norovirus (NoV) and group A rotavirus (RVA) gastroenteritis in Egypt. Literatures published in PubMed and other sources (Science direct, google scholar) on the epidemiology and burden of AdV, AstV, NoV and RV among Egyptian children between 2000-2017 were collected. Data from each study was extracted and compared. The search identified 19 studies. AdV, AstV, NoV and RVA gastroenteritis were identified in $2-20 \%, 0-31 \%, 2.2-30 \%$ and $10.7-76.9 \%$, respectively, with average of $3.6 \%, 7.2 \%, 10.5 \%$ and $32.5 \%$ of all cases of acute gastroenteritis. These viruses were occurred year-around with high detection rates in male and children younger than 12 months. The most common genotypes were HAstV-1 for astrovirus, G1P[8] for rotavirus, GGII.4 for norovirus. Children with AdV, AstV, RVA and NoV-positive acute gastroenteritis were more likely to have vomiting, diarrhea, abdominal pain, fever, various degrees of dehydration ranged from mild to severe dehydration. This systematic review documents that enteric viruses, particularly RVA, are significant pathogens of children diarrhea in Egypt. A vaccine covering multiple genotypes may reduce the morbidity and cost burden of AdV, AstV, RVA and NoV gastroenteritis in Egypt.
\end{abstract}

Keywords: Enteric Virus; Rotavirus; Norovirus; Astrovirus; Adenovirus; Gastroenteritis

\section{Introduction}

Acute diarrheal diseases are a major problem for public health, causing approximately 0.8 million deaths per year affecting mostly children $<5$ years old [1]. Although the deaths occur mostly in developing countries, diarrheal illness is the main cause of morbidity and mortality in children worldwide [2,3]. Enteric viruses are identified as the most significant causative agent of acute gastroenteritis (AGE) in children, accounting for about $70 \%$ of episodes [4]. Four virus families are often associated with AGE in children: adenoviruses (AdV), rotaviruses group A (RVA) and astroviruses (AstV) and noroviruses (NoV) [5].

Rotaviruses, belonging to the Reoviridae family, are classified into 50-P and 35 G-genotypes based on the differences in the nucleotide sequence of VP4 and VP7 genes [6]. RVA with combination of G and $P$ genotypes have been stated in several epidemiological studies $[7,8]$. The most common five genotype combinations are G1P, G2P, G3P, G4P and G9P, causing about $75 \%$ of RVA infections globally [4,8-10]. RVA infections are estimated to cause approximately 453,000 deaths among children below five years of age per year, mostly in developing countries [11].

Noroviruses (NoVs) are identified as the most common cause of AGE in humans, globally [12]. NoVs, within the Caliciviridae family, are small (27-40 $\mathrm{nm}$ in diameter) non-enveloped viruses containing a single-stranded RNA genome with a size of approximately 6.5-7.5 kb. NoV can be classified into 6 genogroups GI-GVI [13]. The three genogroups GI, GII and GIV have been recognized to infect human and they are subdivided into approximately 33 genotypes (9 GI, 22 GII and 2 GIV) [14]. The genotype GII.4 are associated with worldwide outbreaks [14].

Adenoviruses, within Adenoviridae family, possess double-stranded non-enveloped DNA genome. AdVs include 57 different serotypes and they can be subdivided into 7 subgenera (A-G). Adenovirus subgenus
F, including 40 and 41 serotypes, is called an enteric virus because it associated with AGE. The both 40 and 41 serotypes are responsible for about $1-20 \%$ cases of AGE in young children. Also, subgenus A (types 12,18 and 31 ), subgenus $C$ (types 1,2 and 5 ) and subgenus $D$ (types 28 $30,32,37$ and 43-46) have also been implicated with diarrheal diseases $[15,16]$.

Human astroviruses, belonging to Astroviridae family, are nonenveloped viruses with a single-stranded RNA genome. HAst $\mathrm{V}$ have also been identified as a major cause of viral AGE in immunocompromised, children and the elderly subjects. HAstV are subdivided into eight serotypes and HAst $V-1$ is the most prevalent serotype with high seroprevalence rate $(\sim 90 \%)$ in children younger than 5 years [1723]. Routine diagnostic techniques for viral diarrhea are often based on the detection of most common enteric viruses ( $\mathrm{AdV}, \mathrm{AstV}, \mathrm{NoV}$ and RVA) by immunoassays or by molecular methods.

\section{Materials and Methods}

Nineteen articles from Egypt were published between January 2000 and December 2017, have been collected from google scholar, science direct and PubMed websites with the keywords "enteric viruses, adenovirus, astrovirus, norovirus and rotavirus gastroenteritis". All articles published on these websites were collected without specific criteria. Detection of enteric viruses were conducted using a sensitive

*Corresponding author: Mohamed NF Shaheen, Environmental Virology Laboratory, Water Pollution Research Department, Environmental Research Division, National Research Center, Al-Buhouth Street, Giza, Egypt, Tel: +2 01016710071, E-mail: m_nrc2007@yahoo.com

Received August 28, 2018; Accepted September 13, 2018; Published September 18,2018

Citation: Shaheen MNF (2018) Burden of Adenovirus, Astrovirus, Norovirus and Rotavirus Gastroenteritis in Egyptian Children during 2000-2017. J Med Microb Diagn 7: 283. doi:10.4172/2161-0703.1000283

Copyright: @ 2018 Shaheen MNF. This is an open-access article distributed unde the terms of the Creative Commons Attribution License, which permits unrestricted use, distribution, and reproduction in any medium, provided the original author and source are credited. 
Citation: Shaheen MNF (2018) Burden of Adenovirus, Astrovirus, Norovirus and Rotavirus Gastroenteritis in Egyptian Children during 2000-2017. J Med Microb Diagn 7: 283. doi:10.4172/2161-0703.1000283

technique such as an enzyme immunoassay (EIA), polymerase chain reaction (PCR) and reverse-transcriptase polymerase chain reaction (RT-PCR). The prevalence, seasonal variation, gender distribution, age distribution, genotyping of enteric viruses and clinical features were extracted from all collected studies and compared.

The prevalence of enteric viruses as well as RVA genotypes were analyzed by two ways:

a. Overall the period of sample collections

b. During different periods according to the years of sample collections.

\section{Results}

\section{Studies selected for this review}

As depicted in Table 1, we reviewed 19 articles from Egypt contained the following topics: Prevalence of $\operatorname{AdV}(n=7)$, AstV $(n=8)$, NoV $(n=6)$ and RVA $(n=16)$; seasonal variation of $\operatorname{AdV}(n=4), \operatorname{AstV}(n=3), N o V$ $(\mathrm{n}=3)$ and RVA $(\mathrm{n}=10)$; age distribution of $\operatorname{AdV}(\mathrm{n}=6), \operatorname{AstV}(\mathrm{n}=4)$, $\operatorname{NoV}(n=5)$ and RVA $(n=12)$; gender distribution of $\operatorname{AdV~}(n=1)$, AstV $(\mathrm{n}=2), \operatorname{NoV}(\mathrm{n}=1)$ and RVA $(\mathrm{n}=9)$; genotype distribution of AdV $(\mathrm{n}=0)$, AstV $(n=2), \operatorname{NoV}(n=2)$ and RVA $(n=10)$; and disease severity of AdV $(\mathrm{n}=2)$, AstV $(\mathrm{n}=3)$, NoV $(\mathrm{n}=2)$ and RVA $(\mathrm{n}=7)$ [24-42].

\section{Prevalence of viral gastroenteritis}

Nineteen articles from Egypt contained specimens from 7067 children $(6337<5$ years, $230<18$ years, $500<18$ of age) with acute gastroenteritis were tested for the occurrence of $\mathrm{AdV}, \mathrm{AstV}, \mathrm{NoV}$ and RVA. Among 7067 stool specimens from patients with acute diarrhea, 2117 (30\%) were positive for enteric viruses. Overall the periods of sample collection (1995-2017), the most frequently detected virus was rotavirus (ranged from $10.7 \%$ to $76.9 \%$, with average of $32.5 \%$ ), followed by norovirus (ranged from $2.2 \%$ to $30 \%$, with average of $10.5 \%$ ), astrovirus (ranged from $0 \%$ to $31 \%$, with average of $7.2 \%$ ) and adenovirus (ranged from $2 \%$ to $20 \%$, with average of $3.6 \%$ ). The results are summarized in Table 2. To study the prevalence of enteric viruses during the different periods, data from single and combined studies were extracted according to the years of sample collections as fellows: the incidence of AdV gastroenteritis were shown during 2005-2007, 2012$2013,2013-2015,2015-2017$ with detection rates of $2 \%, 6.4 \%, 7 \%$ and $12.8 \%$ respectively $[24,28,30,35,40,41]$. The occurrence of AstV were shown during 1995-1998, 2005-2007, 2007-2009, 2012-2015, 20152017 with detection rates of $31 \%, 3 \%, 39 \%, 2.6 \%$ and $6.4 \%$ respectively $[24,26,27,30,33,35-41]$. The detection rates of NoV in patient diarrhea during 2005-2007, 2007-2009, 2012-2013, 2013-2015, 2015-2017 were $9 \%, 5 \%, 81 \%, 37 \%$ and $30 \%$ respectively $[24,26,28,30,33,35]$.
The prevalence of RVA was shown during the period 200-2002, 20042007, 2007-2009, 2009-2010, 2010-2013, 2013-2015, 2015-2017 with detection rates of $25.2 \%, 37.4 \%, 19 \%, 32 \%, 42 \%, 52.7 \%, 32.8 \%$ of all cases, respectively (Figure 1) [24-26,29,30-37,39-42].

\section{Seasonal distribution of viral gastroenteritis}

Eleven published studies from Egypt as shown in Table 2, stated seasonality distribution of AdV, AstV, NoV and RVA [24,28,29,31,34$37,39,40,42]$. Ten studies reported that the high incidence of viral gastroenteritis was occurred in the cold and warm seasons [24,28,29,31,34-39]. Other two studies reported that the peak incidence of $\mathrm{AdV}, \mathrm{AstV}$, RVA infections were found in spring season [40,42].

\section{Age distribution of children with viral gastroenteritis}

As shown in Table 2, fifteen studies from Egypt contained data on the age distribution [24,28-40,42]. Among them, eleven studies state that the most viral infections were occurred in children younger than 1 years of age $[24,28,31-40,42]$. However, five studies found that the most infections with viral gastroenteritis were detected in the age group 1236 months [30,33,35,38]. Also, one study reported that the most of RVA gastroenteritis was occurred in the age group 6-24 months [29].

\section{Gender distribution of children with viral gastroenteritis}

Eleven studies stated data on gender distribution [29,32-34,36-42]. The frequency of AdV, AstV, RVA and NoV diarrhea were higher in males as compared to the females as shown in Table 2 and Figure 2 $[29,33,34,36,38,40-42]$. However, three studies reported that the most RVA gastroenteritis was found in females as compared to the males $[37,39]$. An equal distribution of RVA diarrhea in males and females was reported in one study [32].

\section{Distribution of astrovirus genotypes in children with diarrhea}

Two studies contained data on astrovirus genotypes [27,38]. Ahmed et al. stated that $H A s t V-1$ was the most circulating type, was found in 9/16 (56\%) of positive samples, followed by HAstV-MLB1 5/16 (31\%) and HAstV VA2 2/16 (12.5\%) [27]. Also, Naficy et al. reported that $H A s t V-1$ was the most frequent type, it was detected in $36 / 83(43.4 \%)$ of positive samples, followed by HAstV-5 13/83(15.6\%), HAstV-8 10/83 (12\%), HAstV-3 10/83 (12\%), HAstV-6 6/83 (7.2\%), HAstV-4 4/83 (4.8\%) and HAstV-2 3/83 (3.6\%) [38].

\section{Distribution of norovirus genotypes in children with diarrhea}

Two studies from Egypt contained data on norovirus genotypes. GGII was the most commonly detected genotype; it was identified in $71 \%$ of the cases, where GGII.4 was the predominated strain, it was identified in $45 \%$ of the cases, followed by GGIIb (22.6\%) and GGII.3

\begin{tabular}{|c|c|c|c|c|c|c|}
\hline Virus & $\begin{array}{l}\text { Prevalence of viral } \\
\text { gastroenteritis }\end{array}$ & Seasonality & Age distribution & Gender distribution & Genotyping & Disease severity \\
\hline Adenovirus & {$[24,28,30,33,35,40,41]$} & {$[24,28,35,40]$} & $\begin{array}{c}{[24,28,30,33,35,40]} \\
41]\end{array}$ & {$[40]$} & - & {$[33,35]$} \\
\hline Astrovirus & $\begin{array}{c}{[24,26,27,28,33,35} \\
38,41]\end{array}$ & {$[24,28,35]$} & {$[24,28,33,38]$} & {$[33,38]$} & {$[27,38]$} & {$[33,35,38]$} \\
\hline Norovirus & {$[24,26,28,30,33,35]$} & {$[24,28,35]$} & {$[24,28,30,33,35]$} & [33] & {$[24,26]$} & {$[33,35]$} \\
\hline Rotavirus & $\begin{array}{c}{[24,25,26,29,30,} \\
31,32,33,34, \\
35,36,37,39,40,41,42]\end{array}$ & $\begin{array}{l}{[24,29,31,34,35,} \\
36,37,39,40,42]\end{array}$ & $\begin{array}{l}{[24,29,30,31,32,33,} \\
34,36,37,39,40,42]\end{array}$ & $\begin{array}{c}{[29,33,34,36,37,39} \\
40,41,42]\end{array}$ & $\begin{array}{c}{[24,25,29,31,34,37,39} \\
40,41,42]\end{array}$ & {$[31,32,33,35,36,39,41]$} \\
\hline
\end{tabular}

Table 1: Literatures of extracted data by virus. 
Citation: Shaheen MNF (2018) Burden of Adenovirus, Astrovirus, Norovirus and Rotavirus Gastroenteritis in Egyptian Children during 2000-2017. J Med Microb Diagn 7: 283. doi:10.4172/2161-0703.1000283

Page 3 of 8

\begin{tabular}{|c|c|c|c|c|c|c|c|c|c|c|}
\hline \multirow[b]{2}{*}{$\begin{array}{c}\text { Reference } \\
\text { number }\end{array}$} & \multirow[b]{2}{*}{ Virus } & \multicolumn{4}{|c|}{ Study characteristics } & \multicolumn{5}{|c|}{ Study results } \\
\hline & & $\begin{array}{l}\text { Year(s) of } \\
\text { Sample } \\
\text { collection }\end{array}$ & $\begin{array}{l}\text { Duration of sample } \\
\text { collection per } \\
\text { month }\end{array}$ & $\begin{array}{l}\text { Age, } \\
\text { years }\end{array}$ & Method & $\begin{array}{c}\text { No. } \\
\text { withAGE }\end{array}$ & $\begin{array}{c}\text { Prevalence } \\
\text { No }(\%)\end{array}$ & $\begin{array}{c}\text { Gender } \\
\text { distribution } \\
\text { No }(\%)\end{array}$ & $\begin{array}{c}\text { Peak } \\
\text { Season }\end{array}$ & $\begin{array}{c}\text { Peak Age } \\
\text { [Month] }\end{array}$ \\
\hline \multirow{4}{*}[24]{} & $\mathrm{AdV}$ & \multirow{4}{*}{ 2006- 2007} & \multirow{4}{*}{12} & \multirow{4}{*}{$<18$} & \multirow{4}{*}{ ELISA } & \multirow{4}{*}{230} & $12(5.2)$ & \multirow{4}{*}{-} & \multirow{4}{*}{ Cold } & \multirow{4}{*}{$<12$} \\
\hline & AstV & & & & & & $2(0.9)$ & & & \\
\hline & NoV & & & & & & $23(10)$ & & & \\
\hline & RVA & & & & & & $76(33)$ & & & \\
\hline [25] & RVA & $2000-2002$ & 24 & $<5$ & ELISA & 1026 & $259(25.2)$ & - & - & - \\
\hline \multirow{3}{*}[26]{} & AstV & \multirow{3}{*}{$2007-2009$} & \multirow{3}{*}{24} & \multirow{3}{*}{$<5$} & \multirow{3}{*}{ RT-PCR } & \multirow{3}{*}{220} & $39(17.7)$ & \multirow{3}{*}{-} & \multirow{3}{*}{-} & \multirow{3}{*}{-} \\
\hline & NoV & & & & & & $5(2.2)$ & & & \\
\hline & RVA & & & & & & $72(32.7)$ & & & \\
\hline$[27]$ & AstV & $2006-2007$ & 12 & $<5$ & RT-PCR & 364 & $23(6.3)$ & - & - & - \\
\hline \multirow{3}{*}{ [28] } & AdV & \multirow{3}{*}{$2005-2007$} & \multirow{3}{*}{24} & \multirow{3}{*}{$<5$} & & & $34(2)$ & & & \\
\hline & AstV & & & & EIA & 2112 & $56(3)$ & - & Warm & $<12$ \\
\hline & NoV & & & & & & 191(9) & & & \\
\hline [29] & RVA & $2009-2010$ & 12 & $<5$ & RT-PCR & 450 & $158(35)$ & $\begin{array}{c}F: 92(58.2) \\
M: 66(42)\end{array}$ & Cold & $6-24$ \\
\hline & AdV & & & & & & $34(6.8)$ & & & \\
\hline$[30]$ & NoV & $2012-2013$ & 12 & $<15$ & RT-PCR & 500 & $81(16.2)$ & - & - & $12-36$ \\
\hline & RVA & & & & & & 195(39) & & & \\
\hline$[31]$ & RVA & $2004-2007$ & 27 & $<2$ & EIA & 348 & $140(40)$ & - & Warm & $<12$ \\
\hline [32] & RVA & $2014-2015$ & 6 & $<5$ & qr R T-PCR & 65 & $50(76.9)$ & $\begin{array}{l}\text { M: } 25(50) \\
\text { F: } 25(50)\end{array}$ & - & $6-12$ \\
\hline & AdV & & & & & & $7(7)$ & - & & $7-12$ \\
\hline & AstV & & & & & & $3(3)$ & $\begin{array}{l}\text { M: 2(66.7), } \\
F: 1(33.3 \%)\end{array}$ & & $13-18$ \\
\hline [33] & NoV & 2013-2015 & 18 & $\leq 24$ & RT-PCR & 100 & $14(14)$ & $\begin{array}{l}M: 8(57.1) \\
F: 6(42.9)\end{array}$ & - & $7-12$ \\
\hline & RVA & & & & & & $37(37)$ & $\begin{array}{l}M: 19(51.4) \\
F: 18(48.6)\end{array}$ & & $7-12$ \\
\hline$[34]$ & RVA & 2011-2012 & 12 & $<2$ & EIA & 197 & $77(39.1)$ & $\begin{array}{l}\text { M: } 50(65) \\
\text { F: } 27(35)\end{array}$ & Winter & $<12$ \\
\hline & AdV & & & & & & $20(20)$ & & & $12-24$ \\
\hline & AstV & & & & $\begin{array}{l}\text { Multiplex RT- } \\
\text { PCR }\end{array}$ & & $14(14)$ & & & - \\
\hline [35] & NoV & 2015-2017 & +24 & $<5$ & & 100 & $30(30)$ & - & Winter & $12-24$ \\
\hline & RVA & & & & ELISA & & $44(44)$ & & & - \\
\hline [36] & RVA & 2007-2009 & 24 & $<5$ & ELISA & 356 & $38(10.7)$ & $\begin{array}{l}\text { M: } 27(71) \\
\text { F: } 11(29)\end{array}$ & Warm & $\leq 6$ \\
\hline$[37]$ & RVA & $2009-2010$ & 12 & $<5$ & RT-PCR & 100 & 19(19) & $\begin{array}{l}\text { M: } 9 / 19(47.4) \\
\text { F: } 10 / 19(52.6)\end{array}$ & Winter & $2-6$ \\
\hline [38] & AstV & 1995 - 1998 & 36 & $<3$ & ELISA & 397 & 123(31) & $\begin{array}{c}\text { M: } 70 / 123(56.9) \\
\text { F: } 53 / 123(43)\end{array}$ & Warm & $\geq 3$ \\
\hline [39] & RVA & $2010-2012$ & 17 & $<5$ & RT-PCR & 92 & $45(48.9)$ & $\begin{array}{l}\text { M: } 22(48.9) \\
F: 23(51.1)\end{array}$ & warm & $6-12$ \\
\hline$[40]$ & AdV & $2015-2016$ & 12 & $<5$ & ELISA & 119 & $8(6.7)$ & $\begin{array}{l}\text { M: } 5(7.2) \\
\quad F: 3(6)\end{array}$ & Spring & $<12$ \\
\hline & RVA & & & & & & $37(31)$ & $\begin{array}{l}\text { M: } 20(54) \\
\text { F: } 17(46)\end{array}$ & & \\
\hline
\end{tabular}


Citation: Shaheen MNF (2018) Burden of Adenovirus, Astrovirus, Norovirus and Rotavirus Gastroenteritis in Egyptian Children during 2000-2017. J Med Microb Diagn 7: 283. doi:10.4172/2161-0703.1000283

Page 4 of 8

\begin{tabular}{|c|c|c|c|c|c|c|c|c|c|c|}
\hline \multirow{3}{*}{ [41] } & AdV & \multirow{3}{*}{2012} & \multirow{3}{*}{4} & \multirow{3}{*}{$<5$} & \multirow{3}{*}{ ELISA } & \multirow{3}{*}{93} & $4(4.3)$ & - & \multirow{3}{*}{-} & \multirow{3}{*}{-} \\
\hline & AstV & & & & & & $2(2.15)$ & - & & \\
\hline & RVA & & & & & & $53(57)$ & $\begin{array}{c}\text { M: } 29(54.7) \\
F: 24(45.3)\end{array}$ & & \\
\hline [42] & RVA & $2015-2016$ & 12 & $<5$ & ELISA & 198 & $56(28.3)$ & $\begin{array}{l}\text { M: 35(61.4) } \\
\text { F: } 21 \text { (37.5). }\end{array}$ & Spring & $1-12$ \\
\hline
\end{tabular}

EIA: Enzyme Immunoassay; ELISA: Enzyme-Linked Immunosorbent Assay; RT-PCR: Reverse Transcriptase Polymerase Chain Reaction; Qr RT-PCR, Quantitative Real Time RT-PCR; M= Male; F= Female.

Table 2: Enteric virus detection among Egyptian children with acute gastroenteritis.

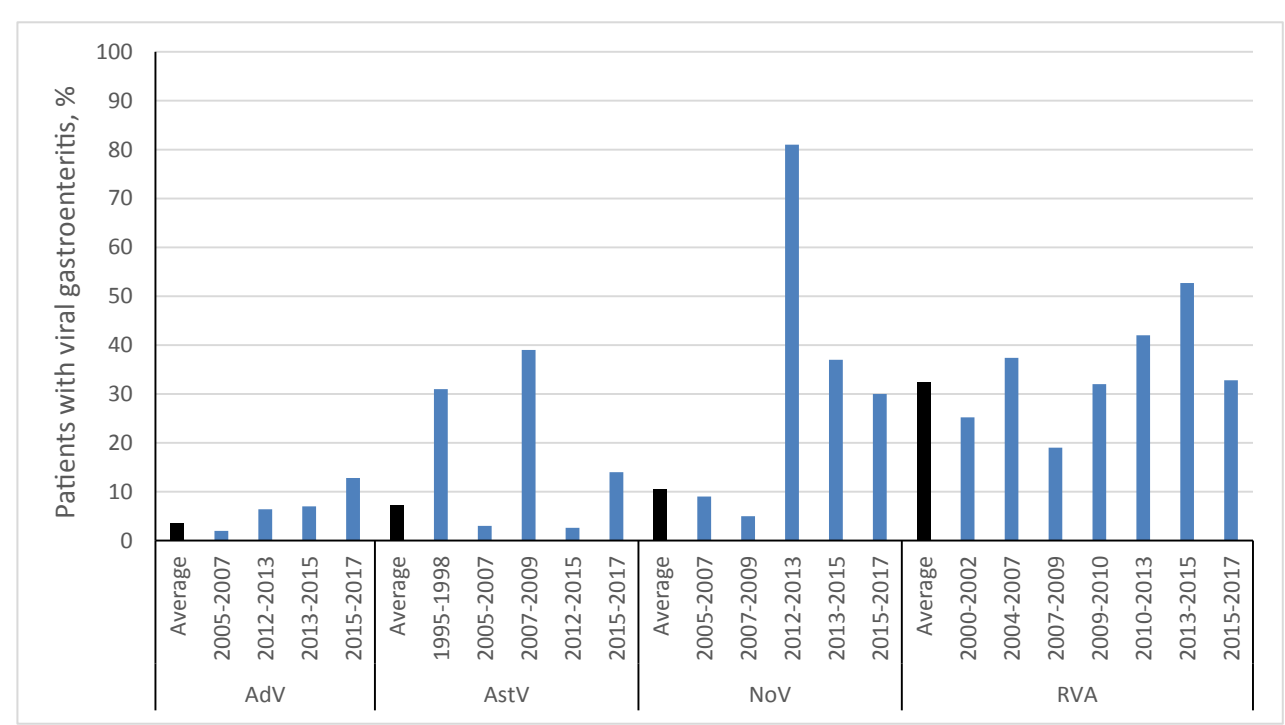

Figure 1: Mean overall percentage of viral distribution in Egyptian children with acute gastroenteritis during different periods.

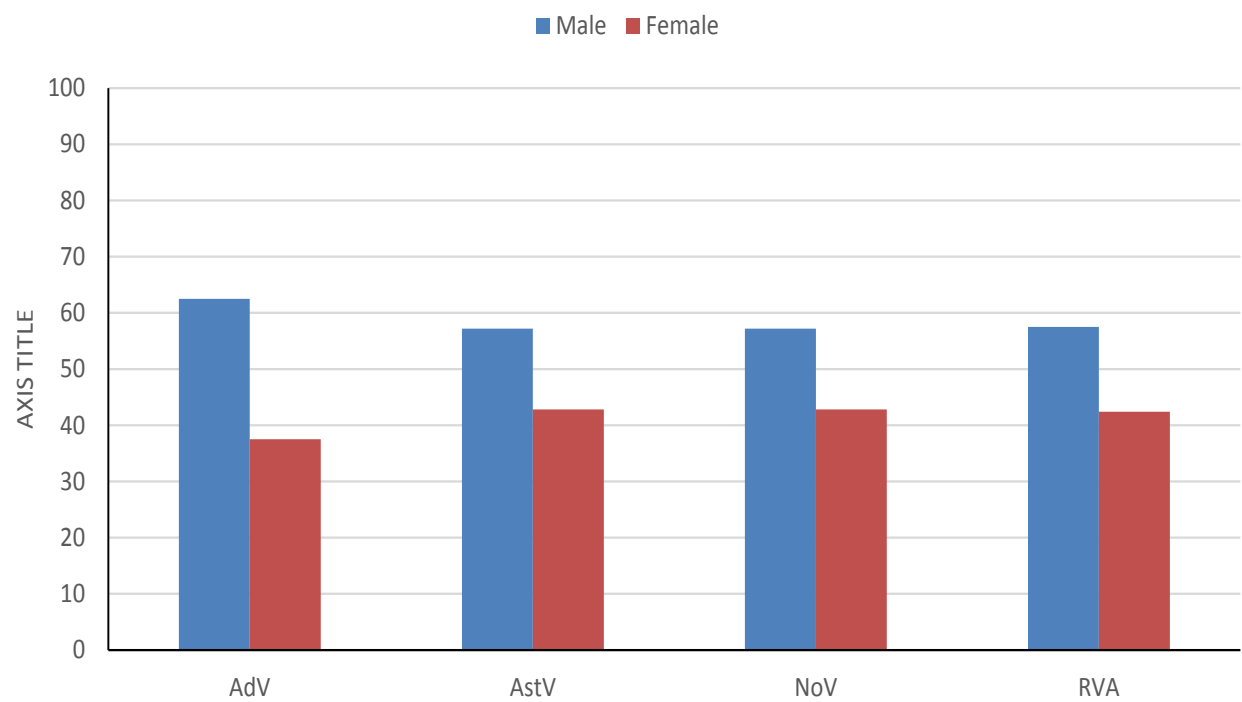

Figure 2: Age distribution of patients with enteric virus diseases.

(13\%). In the same study, GGI was detected in $29 \%$ of all positive samples where GGI.1 and GGI.9 were detected in $9.7 \%$ of all positive specimens while GGI.3, GGI.4, GGI.5 and GGI.15 were detected in $3.2 \%$ of all positive samples [24]. In the second study, GGI was detected in five of 220 (2.2\%) diarrheal samples while GGII was not detected [26].
Distribution of rotavirus genotypes in children with diarrhea

Three studies from Egypt contained data on G types in 233 stool samples from children with acute diarrhea $[29,37,42]$. RVA G1 was the most common strain (93/233) followed by G3 (46/233), G9 (26/233), G4 (19/233), mixed G types (15/233), G10 (4/233), Non-type G (3/233) 
and G2 (2/233). Moreover, seven studies contained 665 diarrheal samples determined RVA G-P combination [24,25,31,34,39,40,41]. $\mathrm{G} 1 \mathrm{P}[8], \mathrm{G} 2 \mathrm{P}[4], \mathrm{G} 3 \mathrm{P}[8]$ were the most frequently detected in tested samples with median $233 / 665,124 / 665,63 / 665$, respectively. $G 1 P[8]$ combination was the only genotype detected in all seven studies with a proportion ranged from $6 / 223$ to $136 / 223$ of the given specimens. Also, Uncommon RVA genotype combinations such as G1P[4], G1P[6], G2P[8], G3[p6], G4p[8], G9P[8], G9P[6], G9P[8] and G12P[6] were detected in multiple articles with a median prevalence of lower than $5 \%$. Rare RVA genotype combinations including G2P[6], G3[P4], G4P[4], G8P [14], G9P [4] and G12P[4] in multiple articles with a median prevalence of lower than $\leq 0.4 \%$ have also been detected (Figure 3 ).

In another way for data analysis, studies contained data on RVA G-P combinations were classified according to years of sample collection into four periods (2000-2002, 2004-2007, 2010-2012, 2015-2017). The periods of 2000-2002 represent one study, 2004-2007 represent pooling of two studies, 2010-2012 represent pooling of three studies, 2015-2017 represent one study [24,25,31,34,39-41]. G1P[8] and G1P[6] genotypes were the only genotypes detected through the four periods. $G 2 P[4]$ and mixed genotypes were detected in all periods except 20152017 of sample collection. G2P[6], G9P[4] and G12P[4] genotypes were detected only during 2004-2007, whereas G3P[6], G4P[4] and G8P[14] genotypes were detected only during 2010-2015 and they did not detect in the other periods of sample collection. G3P [8] and G9P [8] genotypes did not detect during 2000-2002 but they were detected in the other three periods 2000-2002, 2004-2007, 2010-2012 of sample collection. $G 2 P[8], G 9 P[8]$ and partially genotypes were found only during the first two periods 2000-2002 and 2004-2007 of sample collection. G3P[4], $G 4 P[8], G 9 P[6]$ and non-type genotypes were detected only during the periods 2000-2002 and 2010-2015 of sample collection. G1P[4] genotype appeared in all period of sample collection except 20042007 of sample collection. G12P[6] genotype was detected during the period of 2004-2007 and 2010-2012 of sample collection. The results are summarized in Figure 4.

\section{Clinical features, disease severity and Intravenous rehydration}

Eight studies from Egypt provided us data on clinical features of gastroenteritis caused by enteric viruses [31-33,35,36,38,39,41]. The common clinical features resulted from the infections by these viruses were vomiting, diarrhea, abdominal pain, fever, various degrees of dehydration ranged from mild to severe dehydration. Children who received oral solution, oral solution packets to take at home and medication due to RVA infections was reported in one study by El-Shabrawi et al. (2015) [36]. In the same study, convulsions and bloody diarrhea was found in $5 \%$ and $20 \%$ of children infected with RVA, respectively [36]. The median durations of diarrhea due to RVA infection were 3.7 and $3 \pm 2$ days [36,39]. On the other hand, two studies reported that $94.4 \%$ and $18 \%$ of dehydrated children due to RVA gastroenteritis were received Intravenous fluid therapy [36,39]. No deaths were occurred among infected children with viral diarrhea in the all included studies.

\section{Discussion}

Acute Diarrhea is one of the major cause of deaths in infant and young children worldwide, particularly in developing countries [43]. To increase our knowledge about the impact of viral intestinal infections on children, a comprehensive survey on various enteric viruses was carried out in Egypt. This study included commercial EIA, PCR and RT-PCR to detect the most common enteric viruses associated with diarrhea. Our survey demonstrated that RVA is the main enteric virus associated with diarrhea in children, followed by norovirus, astrovirus and adenovirus. The frequency distribution in this survey agrees with results reported from study conducted in Saudi Arabia [44]. As reported by other investigators RVA was recorded as the principal cause for children diarrhea [45-49]. Furthermore, this survey supports the notion that $\mathrm{NoV}$ is the second most viral pathogen of diarrhea in children seeking medical attention [50,51]. Also, this survey supports other study that AstV, AdV are rarely implicated in children gastroenteritis [52].

Although the collected articles in this survey were published between 2000-2018, the sample collections were started from 1995 for astrovirus detection [38]. When we classified this survey into different periods according to the years of sample collections, we found that the higher prevalence of AdV was 12.8\% during the recent years (20152017) of sample collection while the higher prevalence of AstV, NoV,

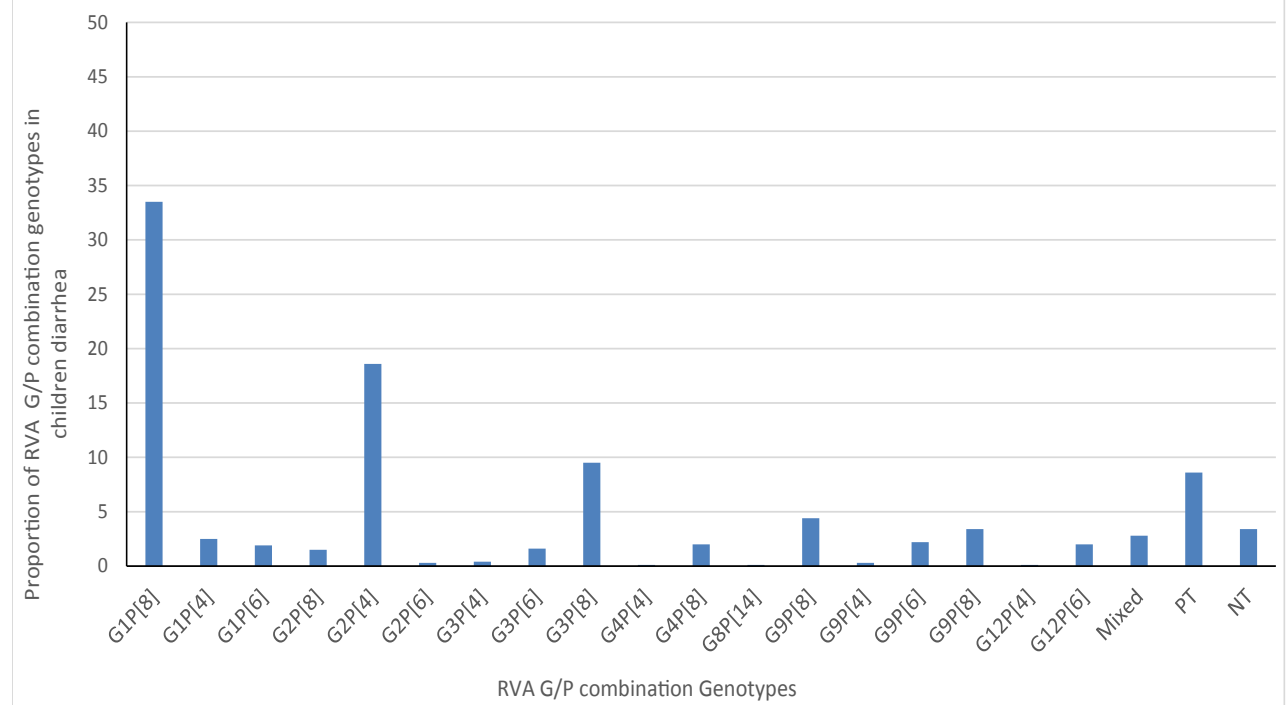

Figure 3: Mean overall proportion of RVA P-G combinations in Egyptian children with acute diarrhea (2006-2016), PT=Partially Typable Serotypes, NT=Non-Typable Serotypes $(n=665)$. 


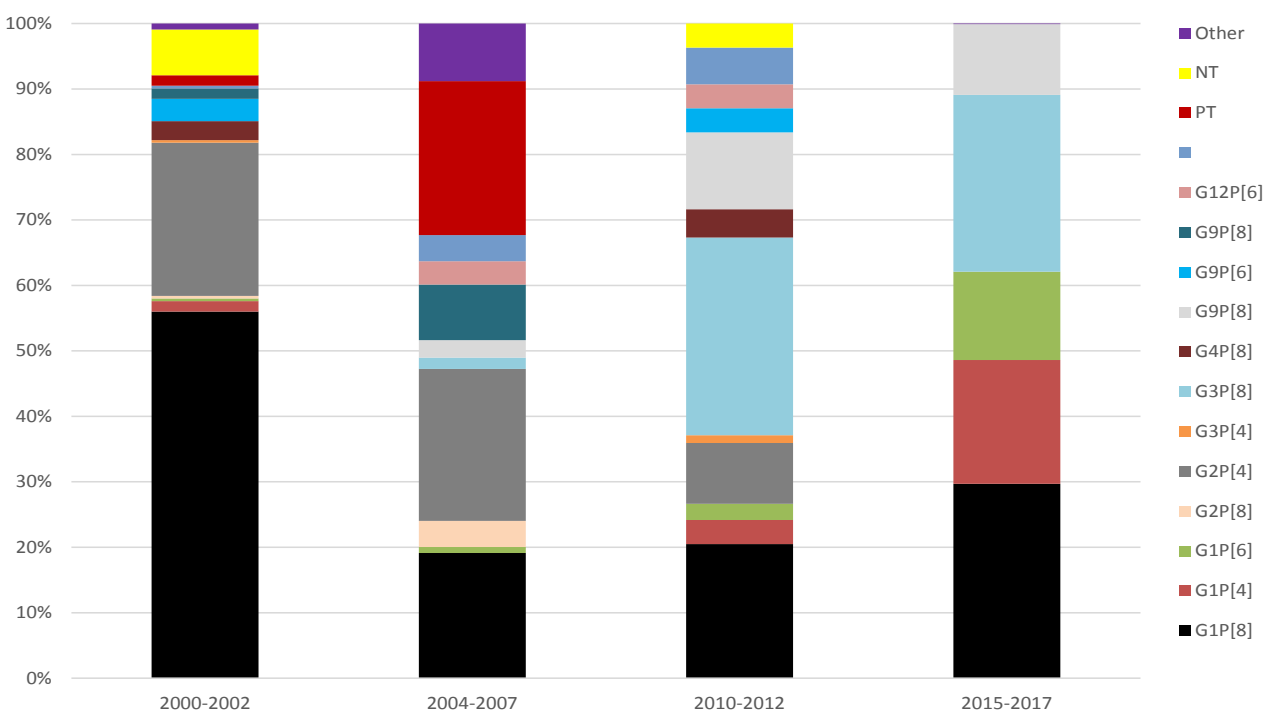

Figure 4: Distribution of RVA G-P combination genotypes among Egyptian children diarrhea during different periods.

RVA gastroenteritis among patients with acute diarrhea were $39 \%, 81 \%$ and 52.7\% during the periods 2007-2009, 2012-2013and 2013-2015 of sample collections, respectively, which have fallen in the recent years (2015-2017) of sample collection to $14 \%, 30 \%$ and $32.8 \%$, respectively. However, no data was available on the detection rates of these viruses in some years. For example, there was no data on the prevalence of AdV, NoV and RVA during 1995-1998. Also, no data was available on the prevalence of AdV, AstV and NoV during 2000-2004.

In this survey, RVA typing showed that G1-G4, G9 and G10 are the circulated rotavirus strains in Egypt where G1 represents the most prevalent strain among children diarrhea. Furthermore, RVA G1P[8] was the most circulating genotype in children with acute diarrhea. This result agrees with studies from Egypt and other countries [25,39,40,53-55]. G2P[4] was the most second circulating genotypes after $G 1 P[8]$ and this finding agree with other studies from Vietnam and sub-Saharan Africa [54,55]. Khoury et al. reported that G1P[8] and GP[4] were the most circulated genotype combination in the Middle Eastern and North African, based on data collected from 1999 and 2009 [54]. These findings highlight the socioeconomic impact of the current vaccine in prevention of rotavirus diarrhea and confirm that RotaTeq vaccine (Whitehouse Station, NJ, USA), containing a mixture of 5 human serotypes G1-G4 plus $\mathrm{P}[8]$ and Rotarix vaccine (GlaxoSmithKline, Rixensart, Belgium), containing G1P[8], appear to be effective in reducing RVA diarrhea in Egypt. However, updating vaccine formulation are needed to contain other circulating serotypes such as G9 and G10 and the other predominant genotypes of RVA such as $G 2 P[4]$ in Egypt.

NoV typing showed that NoV GGII.4 was the most detected genotype in Egyptian children diarrhea [24]. This observation agrees with previous studies from Tunisia, Australia and Japan [56-59]. However, this disagrees with a previous study from Egypt identifying GGI strains as the most circulated strains in children diarrhea [26]. Also, our analysis revealed that HAstV-I was the most prevalent genotype among Egyptian children with diarrhea and this finding agree with previous studies from Australia, Brazil and Hungary [60-62]. The variation in the detection rates of enteric viruses in the included studies can be explained by the variance in the conditions of these studies, such as the difference in the location of sample collection, number of tested samples, season of sample collection, concentration of viral antigens in the collected samples and the sampling methods.

The higher rates of AdV, AstV, NoV and RV antigens in the present survey were found in children $\leq 12$ years of age. This observation may be resulted from the protection which acquired by maternal antibodies during the first year of child life then by the immunity which given after two years of life due to repeated infections [63]. Based on this finding, preventive strategies should be carried out during infancy. Furthermore, most of the included studies in this survey reported that males were more sensitive than females for infection with enteric viruses. Similar results were reported in studies from Jordan, Tunisia, Indonesia and Gabon [64-67]. In the current survey, enteric viral infections were found thought the year including cold, warm, spring seasons and this was reported in other studies [50,52,56,60,62]. The main symptoms of $\mathrm{AdV}$, AstV, NoV and RVA gastroenteritis were vomiting, diarrhea, abdominal pain, fever and dehydration. These symptoms were reported in several reports conducted in Venezuela, Indonesia, Japan and France $[51,66,68,69]$. Study limitations are worth mentioning. The included articles in this survey are contained little data on $\mathrm{AstV}$ and NoV genotyping whereas no data was available on $\mathrm{AdV}$ genotyping. Moreover, no data was available on the burden of these viruses in terms of diarrhea duration, mortality, economic burden and healthcare resource utilization [24,26-28].

\section{Conclusion}

Enteric viruses, especially RVA, gastroenteritis is a common illness associated with significant morbidity in Egyptian children. The results of this study provide useful data to public health. Furthermore, this genetic diversity of AstV, NoV, RVA types in Egypt have been reported in this survey and based on these data updating vaccine formulation, covering the most common serotypes may help to decrease the burden of gastroenteritis resulted from the infections by these viruses in the Egypt.

\section{References}

1. Liu L, Johnson HL, Cousens S, Perin J, Scott S, et al. (2000) Child Health Epidemiology Reference Group of WHO and UNICEF Global, regionaland 
Citation: Shaheen MNF (2018) Burden of Adenovirus, Astrovirus, Norovirus and Rotavirus Gastroenteritis in Egyptian Children during 2000-2017. J Med Microb Diagn 7: 283. doi:10.4172/2161-0703.1000283

national causes of child mortality: An updated systematic analysis for 2010 with time trends since 2000. Lancet. 379: 2151-2161.

2. WHO (2011) World Health Statistics. 2011 World Health Organization, Geneva, Switzerland.

3. Wilhelmi I, Roman E, Sanchez-Fauquier A (2003) Viruses causing gastroenteritis. Clin Microbiol Infect 9: 247-262.

4. Chow CM, Leung AK, Hon KL (2010) Acute gastroenteritis from guidelines to real life. Clin Exp Gastroenterol 3: 97-112.

5. Biscaroa V, Piccinellia G, Gargiuloa F, lanirob G, Caruso A, et al. (2018) Detection and molecular characterization of enteric viruses in children with acute gastroenteritis in Northern Italy. Infect Genet Evol 60 :35-41.

6. Matthijnssens J, Ciarlet M, McDonald SM, Attoui H, Banyai K, et al. (2011) Uniformity of rotavirus strain nomenclature proposed by the Rotavirus Classification Working Group (RCWG). Arch Virol 156:1397-1413.

7. Iturriza-Gomara M, Daliman T, Bottiger B, Buesa J, Diedrich S, et al. (2011) Rotavirus genotypes co-circulating in Europe between 2006 and 2009 as determined by EuroRotaNet, a pan-European collaborative strain surveillance network. Epidemiol Infect 139: 895-909.

8. Matthijnssens J, Van Ranst M (2012) Genotype constellation and evolution of group A rotaviruses infecting humans. Curr Opin Virol 2: 426-433.

9. Santos N, Hoshino $Y$ (2005) Global distribution of rotavirus serotypes/ genotypes and its implication for the development and implementation of an effective rotavirus vaccine. Rev Med Virol 15: 29-56.

10. Ruggeri FM, Delogu R, Petouchoff T, Tcheremenskaia O, De Petris S, et al. (2011) Molecular characterization of rotavirus strains with diarrhea in Italy, 2007-2009. J Med Virol 83: 1657-1668.

11. Tate JE, Burton AH, Boschi-Pinto C, Parashar UD (2000-2013) World Health Organization-Coordinated Global Rotavirus Surveillance Network (2016) Global, regionaland national estimates of rotavirus mortality in children $<5$ years of age. Clin Infect Dis 12: S96-S105.

12. van Beek J, Ambert-Balay $\mathrm{K}$, Botteldoorn N, Eden JS, Fonager J, et al (2013) Indications for worldwide increased norovirus activity associated with emergence of a new variant of genotype II.4, late 2012. Euro Surveill 18: 8-9.

13. Martella V, Decaro N, Lorusso E, Radogna A, Moschidou P, et al. (2009) Genetic heterogeneity and recombination on canine noroviruses. J Virol 83: 11391-11396.

14. Vinje $\mathrm{J}$ (2015) Advances in laboratory methods for detection and typing of norovirus. J Clin Microbiol 53: 373-381.

15. Dey RS, Ghosh S, Chawla-Sarkar M, Panchalingam S, Nataro JP, et al. (2011) Circulation of a novel pattern of infections by enteric adenovirus serotype 41 among children below 5 years of age in Kolkata, India. J Clin Microbiol 49: 500-505.

16. Li L, Phan TG, Nguyen TA, Kim KS, Seo JK, et al. (2005) Molecular epidemiology of adenovirus infection among pediatric population with diarrhea in Asia. Microbiol Immunol 49: 121-128.

17. Finkbeiner SR, Holtz LR, Jiang Y, Rajendran P, Franz CJ, et al. (2009) Human stool contains a previously unrecognized diversity of novel astroviruses. Viro J 6: 161

18. Johnson C, Hargest V, Cortez V, Meliopoulos VA, Schultz-Cherry S (2017) Astrovirus pathogenesis. Viruses 9: 22.

19. Coppo P, Scieux C, Ferchal F, Clauvel JP, Lassoued K (2000) Astrovirus enteritis in a chronic lymphocytic leukemia patient treated with fludarabine monophosphate. Ann Hematol 79: 43-45.

20. Moser LA, Schultz-Cherry S (2005) Pathogenesis of astrovirus infection. Viral Immunol 18: 4-10.

21. Jarchow-Macdonald AA, Halley S, Chandler D, Gunson R, Shepherd SJ et al. (2015) First report of an astrovirus type 5 gastroenteritis outbreak in a residential elderly care home identified by sequencing. J Clin Virol 73: 115-119.

22. Bosch A, Pinto RM, Guix S (2014) Human astroviruses. Clin Microbiol Rev 27: 1048-1074.

23. Koopmans MP, Bijen MH, Monroe SS, Vinje J (1998) Age-stratified seroprevalence of neutralizing antibodies to astrovirus types 1 to 7 in humans in the Netherlands. Clin Diagn Lab Immunol 5: 33-37.
24. Kamel AH, Ali MA, El-Nady HG, De Rougemont A, Pothier P, et al. (2009) Predominance and circulation of enteric viruses in the region of Greater Cairo Egypt. J Clin Microbiol 47: 1037-1045.

25. Matson DO, Abdel-Messih IA, Schlett CD, Bok K, Wienkopff T, et al. (2010) Rotavirus genotypes among hospitalized children in Egypt, 2000-2002. J Infect Dis 202: S263-S265

26. El-Senousy MW, El-Gamal SM, Mousa AA, El-Hawary ES, Fathi NM, et al (2014)Prevalence of Noroviruses among Detected Enteric Viruses in Egyptian Aquatic Environment. World Applied Sciences Journal 32: 2186-2205.

27. Ahmed SF, Sebeny PJ, Klena JD, Pimentel G, Mansour A, et al. (2011) Nove astroviruses in children, Egypt. Emerg Infect Dis 17: 2391-2393.

28. El-Mohammady H, Mansour A, Shaheen HI, Henien NH, Motawea MS, et al (2012) Increase in the detection rate of viral and parasitic enteric pathogens among Egyptian children with acute diarrhea. J Infect Dev Ctries 6: 774-781.

29. Hashem S, Shoman SA, Mohamed AF (2012) Isolation and molecular genotyping of group A rotavirus strains circulating among Egyptian infants and children. Egyp J Med Microbiol 21: 11-20.

30. Zaghloul MZ, El-Sahn SF, Galal ZA (2013) Confection of Rotavirus group A Norovirus and Adenovirus in Egyptian children with Gastroenteritis. Life Sci J 10: $848-852$

31. Ahmed SF, Mansour AM, Klena JD, Husain TS, Hassan KA, et al. (2014) Rotavirus genotypes associated with acute diarrhea in Egyptian infants. Pediatr Infect Dis J 33: S62-S68.

32. Ibrahim SB, El-Bialy AA, Mohammed MS, El-Sheikh AO, Elhewala A, et al. (2015) Detection of Rotavirus in children with acute gastroenteritis in Zagazig University Hospitals in Egypt. Electron physician 7: 1227-1233.

33. El-Mosallamy WA, Awadallah MG, El-Fattah A, Diaa M, Aboelazm AA (2015) Human Bocavirus among Viral Causes of Infantile Gastroenteritis. Egypt Journal Med Microbiol 38: 1-7.

34. Shoeib AR, Hull JJ, Jiang B (2015) Rotavirus G and P types in children with acute diarrhea in Cairo, Egypt, 2011-2012. J Egypt Public Health Assoc 90: 121-124.

35. Zaki ME, El-Kheir NA (2017) Molecular study of astrovirus, adenovirus and norovirus in community acquired diarrhea in children: One Egyptian center study. Asian Pac J Trop Biomed 7: 987-990.

36. El-Shabrawi M, Salem M, Abou-Zekri M, El-Naghi S, Hassanin F, et al. (2015) The burden of different pathogens in acute diarrhoeal episodes among a cohor of Egyptian children less than five years old. Prz Gastroenterol 10: 173-180.

37. EL-Meleigy MA, El-Esnawy NA (2010) Molecular Characterization of Rotavirus Infection among Egyptian Children. New Egypt J Med 42: 443.

38. Naficy AB, Rao MR, Holmes JL, Abu-Elyazeed R, Savarino SJ, et al. (2000) Astrovirus diarrhea in Egyptian children. J Infect Dis 182: 685-690.

39. Saudy N, Elshabrawy WO, Megahed A, Foad MF, Mohamed AF (2016) Genotyping and clinicoepidemiological characterization of rotavirus acute gastroenteritis in Egyptian children. Pol J Microbiol 65: 433-442.

40. Allayeh AK, El-Baz RM, Saeed NM, El-Sayed M (2018) Detection and Genotyping of Viral Gastroenteritis in Hospitalized Children Below Five Years Old in Cairo, Egypt. Arch Pediatr 6: e60288.

41. Elnady H, Abdelsamie O, Sallam S, Sherif L, Kholoussi N (2015) Genotyping of rota virus causing gastroenteritis in Egyptian children. Res J Pharmacol Biol Chem Sci 7: 512-521.

42. Shaheen M, El-Daim AS, Hosseney EN, Shoeib AR, Ali MA (2017) Molecular characterization of rotavirus strains causing gastroenteritis in children under 5 years in Cairo, Egypt. MOJ Public Health 6: 00187.

43. Lopez-de-Andres A, Jimenez-Garcia R, Carrasco-Garrido P, Alvaro-Meca A, Galarza PG, et al. (2008) Hospitalizations associated with rotavirus gastroenteritis in Spain, 2001-2005. BMC Public Health 8: 109.

44. Tayeb HT, Dela Cruz DM, Al-Qahtani A, Al-Ahdal MN, Carter MJ (2008) Enteric viruses in pediatric diarrhea in Saudi Arabia. J med virol 80: 1919-1929.

45. Ouédraogo N, Kaplon J, Bonkoungou IJ, Traoré AS, Pothier P (2016) Prevalence and genetic diversity of enteric viruses in children with diarrhea in Ouagadougou, Burkina Faso. PLoS One. 11: e0153652.

46. Ren Z, Kong Y, Wang J, Wang Q, Huang A, et al. (2013) Etiological study of enteric 
Citation: Shaheen MNF (2018) Burden of Adenovirus, Astrovirus, Norovirus and Rotavirus Gastroenteritis in Egyptian Children during 2000-2017. J Med Microb Diagn 7: 283. doi:10.4172/2161-0703.1000283

viruses and the genetic diversity of norovirus, sapovirus, adenovirusand astrovirus in children with diarrhea in Chongqing, China. BMC infect dis 13: 412

47. Silva PA, Stark K, Mockenhaupt FP, Reither K, Weitzel T (2008) Molecular characterization of enteric viral agents from children in northern region of Ghana. J med virol 80: 1790-1798.

48. Nguyen TA, Yagyu F, Okame M, Phan TG, Trinh QD, et al. (2007) Diversity of viruses associated with acute gastroenteritis in children hospitalized with diarrhea in Ho Chi Minh City, Vietnam. J med virol 79: 582-590.

49. Bicer S, Col D, Erdag GC, Giray T, Gurol Y (2014) A retrospective analysis of acute gastroenteritis agents in children admitted to a university hospital pediatric emergency unit. Jundishapur J Microbiol 7: e9148.

50. Glass RI, Parashar UD, Estes MK (2009) Norovirus gastroenteritis. N Engl J Med 36: 1776-1785.

51. Gonza'lez GG, Ferdinando LF, Ludert EJ (2011) Molecular Epidemiology of Enteric Viruses in Children With Sporadic Gastroenteritis in Valencia, Venezuela. J Med Virol 83: 1972-1982.

52. Sdiri-Loulizi K, Gharbi-Khélifi H, De Rougemont A, Chouchane S, Sakly N (2008) Acute infantile gastroenteritis associated with human enteric viruses in Tunisia. J clin microbiol 46: 1349-1355.

53. Van Man N, Luan LT, Trach DD, Thanh NT, Tu PV (2005) Epidemiologica profile and burden of rotavirus diarrhea in Vietnam: 5 years of sentinel hospital surveillance, 1998-2003. J Infect Dis 1: S127-32.

54. Khoury H, Ogilvie I, El-Khoury AC, Duan Y, Goetghebeur MM (2011) Burden of rotavirus gastroenteritis in the Middle Eastern and North African pediatric population. BMC Infect Dis 11: 9.

55. Mwenda JM, Ntoto KM, Abebe A, Enweronu-Laryea C, Amina I, et al. (2010) Burden and epidemiology of rotavirus diarrhea in selected African countries: preliminary results from the African Rotavirus Surveillance Network. J Infect Dis 202: S5-11.

56. Sdiri-Loulizi K, Ambert-Balay K, Gharbi-Khelifi H, Sakly N, Hassine M, et al. (2009) Molecular epidemiology of norovirus gastroenteritis investigated using samples collected from children in Tunisia during a four-year period: detection of the norovirus variant GGII. 4 Hunter as early as January 2003. J Clin Microbiol 47: 421-429.

57. Kirkwood CD, Clark R, Bogdanovic-Sakran N, Bishop ARF (2005) A 5-year study of the prevalence and genetic diversity of human caliciviruses associated with sporadic cases of acute gastroenteritis in young children admitted to hospital in Melbourne, Australia (1998-2002). J Med Virol 77: 96-101.

58. Phan TG, Takanashi S, Kaneshi K, Ueda Y, Nakaya S (2006) Detection and genetic characterization of norovirus strains circulating among infants and children with acute gastroenteritis in Japan during 2004-2005. Clin Lab 52 519-525.
59. Guo L, Song J, Xu X, Ren L, Li J, et al. (2009) Genetic analysis of norovirus in children affected with acute gastroenteritis in Beijing, 2004-2007. J Clin Virol 44: $94-98$

60. Palombo EA, Bishop RF (1996) Annual incidence, serotype distributionand genetic diversity of human astrovirus isolates from hospitalized children in Melbourne, Australia. J Clin Microbiol 34: 1750-1753.

61. Gabbay YB, Da Luz CR, Costa IV, Cavalcante-Pepino EL, Sousa MS, et al. (2005) Prevalence and genetic diversity of astroviruses in children with and without diarrhea in São Luís, Maranhão, Brazil. Mem Inst Oswaldo Cruz 100 709-714.

62. Jakab F, Meleg E, Bányai K, Melegh B, Tímár L, et al. (2004) One-year survey of astrovirus infection in children with gastroenteritis in a large hospital in Hungary: Occurrence and genetic analysis of astroviruses. J Med Virol 74: 71-77.

63. Durmaz R, Kalaycioglu AT, Acar S, Bakkaloglu Z, Karagoz A, et al. (2014) Turkish Rotavirus Surveillance Network: Prevalence of rotavirus genotypes in children younger than 5 years of age before the introduction of a universal rotavirus vaccination program: report of rotavirus surveillance in Turkey. PLoS One 9: e113674.

64. Youssef M, Shurman A, Bougnoux ME, Rawashdeh M, Bretagne S, et al. (2000) Bacterial, viral and parasitic enteric pathogens associated with acute diarrhea in hospitalized children from Northern Jordan. FEMS Immunol Med Microbio 28: 257-263.

65. Soltani MS, Ben Salah A, Bouanene I, Trabelsi A, Sfar MT, et al. (2015) Epidemiology and medical cost of hospitalization due to rotavirus gastroenteritis among children under 5 years of age in the central-east of Tunisia. East Mediterr Health J 21: 584-590.

66. Subekti D, Lesmana M, Tjaniadi P, Safari N, Frazier E, et al. (2002) Incidence of Norwalk-like viruses, rotavirus and adenovirus infection in patients with acute gastroenteritis in Jakarta, Indonesia. FEMS Immunol Med Microbiol 33: 27-33.

67. Lekana-Douki SE, Kombila-Koumavor C, Nkoghe D, Drosten C, Drexler JF, et al. (2015) Molecular epidemiology of enteric viruses and genotyping of rotavirus A, adenovirus and astrovirus among children under 5 years old in Gabon. Int $J$ Infect Dis 34: $90-95$.

68. Nakanishi K, Tsugawa T, Honma S, Nakata S, Tatsumi M, et al. (2009) Detection of enteric viruses in rectal swabs from children with acute gastroenteritis attending the pediatric outpatient clinics in Sapporo, Japan. J Clin Virol 46: 94-97.

69. Le Guyader FS, Le Saux JC, Ambert-Balay K, Krol J, Serais O, et al. (2008) Aichi virus, norovirus, astrovirus, enterovirusand rotavirus involved in clinical cases from a French oyster-related gastroenteritis outbreak. J Clin Microbio 46: 4011-4017. 